\title{
The Impact of Personalized Preventive Care on Health Care Quality, Utilization, and Expenditures
}

\author{
Shirley Musich, PhD, ${ }^{1}$ Shaohung Wang, PhD, Kevin Hawkins, PhD, and Andrea Klemes, DO, FACE ${ }^{2}$
}

\begin{abstract}
The objective of this study was to evaluate the impact on health care utilization and expenditure trends over time of a personalized preventive medicine program delivering individualized care focused on lifestyle behavior modification, disease prevention, and compliance with quality-related metrics. MD-Value in Prevention (MDVIP) is a network of affiliated primary care physicians who utilize a model of health care delivery based on an augmented physician-patient relationship and focused on personalized preventive health care. Multivariate modeling was used to control for demographics, socioeconomics, supply of health care services, and health status among 10,186 MDVIP members and randomly selected, matched nonmembers. Health care utilization and expenditure trends were tracked from the pre period prior to member enrollment for a period of up to 3 years post enrollment. MDVIP members experienced reduced utilization of emergency room and urgent care services compared to nonmembers. Program savings ranges indicated that, over time, increasing percentages of members achieved cost savings compared to nonmembers. Older age groups were more likely to realize savings in the early years with preventive activities indicating condition management, and younger age groups were most likely to achieve savings by the third year after enrollment. These results indicate that a primary care model based on an enhanced physician-patient relationship and focused on quality and personalized preventive care within a time frame of 3 years can achieve positive health care expenditure outcomes and improved health management.
\end{abstract}

\section{Introduction}

$\mathbf{E}$ MPLOYERS HAVE INDEPENDENTLY IMPLEMENTED health management programs designed to improve the health of their employee and spouse populations and as one of several strategies to mitigate increasing health care expenditure trends and improve productivity. ${ }^{1}$ A 2013 national employer survey by the Kaiser Foundation found that $77 \%$ of employers offering health care benefits also sponsored at least 1 wellness program. ${ }^{2}$ These programs are based on wellestablished research documenting that modifiable lifestyle behaviors are associated with health care expenditures ${ }^{3-7}$; more importantly, as health risks change (improve or increase), health care expenditures follow those changes. ${ }^{8-10}$ Thus, programs can be positioned to facilitate risk improvement as well as to maintain health among those who currently have few health risks and/or no chronic conditions.
Economic evaluations (return on investment [ROI]) of welldesigned, employer-based health management programs have indicated health care expenditure savings generally within 2 to 3 years of program initiation, in addition to longer range savings in subsequent years. ${ }^{11-16}$ Most comprehensive employer health management programs are administered by selected vendors and directed by dietitians, exercise physiologists, and/ or nurse counselors outside of the direct purview of primary care physicians (PCPs). Physician reviews are generally positioned to be provided for those with very high health risks and/ or complex medical issues (ie, high health care expenditures). ${ }^{17}$

Additionally, health care professionals, especially PCPs, can motivate patients under their care to implement lifestyle modifications. Research has shown that adults who recalled receiving advice from a physician or health care professional were more likely to change their eating habits, exercise, maintain a healthy weight, and/or reduce sodium and

\footnotetext{
${ }^{1}$ Advanced Analytics, Optum, Ann Arbor, Michigan.

${ }^{2}$ MDVIP, Boca Raton, Florida.
}

(C) Musich et al, 2016. Published by Mary Ann Liebert, Inc. This Open Access article is distributed under the terms of the Creative Commons Attribution Noncommercial License (http://creativecommons.org/licenses/by-nc/4.0/) which permits any noncommercial use, distribution, and reproduction in any medium, provided the original author(s) and the source are credited. 
alcohol intake. ${ }^{18}$ However, even though PCPs identified lifestyle counseling as a key area of their work, counseling is not offered consistently during office visits. ${ }^{19}$ Physicians who did provide lifestyle counseling often were influenced by their own personal health habits: those who exercised, were nonsmokers, and maintained healthy dietary habits were more likely to counsel on these topics. ${ }^{20}$ Obstacles to effective lifestyle counseling by PCPs have been identified, including lack of time, reimbursement, and training, as well as physician skepticism regarding patient adherence. ${ }^{21,22}$

Wellness and prevention strategies and programs implemented through an employer or directed by a physician can minimize the progression of individuals from lower risk status (whether measured as no/few health risks or as no disease) to higher risk status (more health risks and/or newly diagnosed disease) as they age. Improved health over time can provide more quality years of life for the individual, reduce the prevalence of chronic disease and disability, as well as mitigate health care expenditures during a lifetime. ${ }^{17,23,24}$ Maintaining healthy behaviors in midlife (ages $40-50$ years) has been shown to be predictive of higher percentages of morbidity-free survival in older age (eg, 85 years). ${ }^{25,26}$

A recent report from the Milken Institute supports this perspective. Lifestyle modifications that include healthy eating, physical activity, and nonsmoking, along with compliance with other clinical preventive services, can be costeffective strategies to moderate the development of chronic conditions. ${ }^{27}$ For instance, strategies to reduce heart disease have been most successful in lowering the prevalence and reducing the economic burden of this disease. ${ }^{28}$ Much credit for this reduced trend is associated with antismoking initiatives. Furthermore, identifying strategies for remaining healthy, vigorous, and disability-free at older ages has become a major priority, as reflected by the US Surgeon General's Healthy People 2020 objectives for older people. ${ }^{29}$

Personalized medicine is a relatively new approach to health care delivery that seeks to leverage the physician in promoting healthy lifestyle behaviors, identifying and preventing disease, addressing the issues of care coordination, and providing preventive care to populations of employees and their spouses. ${ }^{30-32}$ The model is based on individualized care, integrating personalized preventive medicine and wellness management, while delivering high levels of coordination within the treatment milieu. The delivery system includes greater focus on evidence-based preventive services, increased physician availability to improve management of patient health, and increased access to other health care resources. ${ }^{30-32}$

The purpose of this study is to evaluate the impact of a personalized preventive care program on health care utilization and expenditure trends for up to 3 years post enrollment. In addition, characteristics and percentages of those individuals who achieved positive cost savings (defined as exceeding monthly membership fees) in years 1,2 , and 3 were documented.

\section{Methods}

\section{MD-Value in Prevention (MDVIP) practice model}

MDVIP's model of comprehensive management focuses on personalized preventive health care by delivering an annual 60to 90-minute appointment that includes health screenings (eg, depression, anxiety, sleep, nutrition, sexual function, vision, hearing), diagnostics (eg, screening for diabetes, bone disease, cardiovascular disease), and personalized coaching and online tools for nutrition and exercise for a membership fee (paid by the patient) of approximately $\$ 125$ to $\$ 170$ per month..$^{30-32}$ The patient receives an "executive-style physical" and works with his or her physician to achieve identified wellness goals. Practices are limited to no more than 600 patients per physician, allowing physicians added time and resources to deliver additional services and provide personalized attention required for management of each patient's relevant health issues. With smaller practice sizes, members receive same-day or next-day appointments for urgent and nonurgent care and the ability to reach their PCP 24 hours a day by phone, e-mail, or text. Physicians also work with their patients out of the office to teach them how to achieve their goals with events like "walk with the doc," "ride (bicycles) with the doc" or "shop (grocery stores) with the doc."

The network currently includes more than 700 affiliated physicians practicing in the model and more than 250,000 patients nationally. Affiliated physicians have an average age of 59 and are $70 \%$ internists and 30\% family practitioners. On average, members are 66 years of age and $50 \%-55 \%$ are enrolled in employer-funded health plans.

The model is not a third-party payer (eg, health insurance) and the fees cover only the extended prevention and wellness services provided by the PCP; therefore, members still pay, via conventional mechanisms (ie, health insurance) for inpatient and outpatient visits, services provided by specialists, and other medical services (eg, laboratories, $\mathrm{X}$-rays). The underlying premise of the model is that the focus on prevention and wellness and the additional time, attention, and access to physicians (ie, higher quality of care delivery) will lead to better health status, lower emergency room (ER) visits and hospital utilization, and ultimately lower health care expenditures. Table 1 summarizes key distinguishing characteristics of MDVIP practices compared to traditional practices as experienced by employees and spouses in employer-sponsored health plans.

\section{Study population}

MDVIP members were identified from UnitedHealthcare employer-sponsored health plan databases using 2009-2014 enrollment files provided by MDVIP. Eligibility for this study was defined as being between the ages of 35 to 84 years and having continuous health plan membership with a minimum of 3 months prior to MDVIP enrollment and a minimum of 3 months and up to 36 months following MDVIP enrollment during the years 2009-2014. Nonmembers were randomly selected from UnitedHealthcare employer-sponsored databases. Eligibility for nonmembers was defined as for members: ages 35 to 84 years and having continuous health plan membership for a minimum of 3 months prior to a matched range of enrollment dates with a minimum of 3 months follow-up and up to 36 months postenrollment dates (2009-2014). Health care expenditure outliers were removed at the $99.5^{\text {th }}$ percentile along with those with no claims (ie, \$0) in a given year to provide equalized distributions of health care expenditures for members and nonmembers.

\section{Control variables}

Control variables included member demographics (eg, age, sex, plan type, region of the United States, metropolitan 
Table 1. Characteristics of MDVIP Practices and Traditional Practices

MDVIP Practice

Physicians focused on early risk detection and prevention of disease

$\leq 600$ patients per physician

8-12 patients per day seen by physician

Care delivered only by personal physician

30-90 minutes per visit

Personal physician available 24/7

MDVIP physician network available when traveling

Coordination of care (ie, specialists, hospitalists)

Patients get all their questions answered

Same-day appointments

On-time appointments

Proactive coaching outside of the office
Traditional Practice

Physicians focused on diagnosis and control

of chronic conditions

$>2400$ patients per physician

30-35 patients per day seen by available provider

Care delivered by available physicians/extenders

$<8$ minutes per visit

Emergency "on-call service"

Walk-in clinics or emergency rooms when traveling

Little coordination of care or follow-up

Patients don't have time to ask questions

Average 4-6 weeks for appointment

Waiting rooms

Patient responsible for own education and exercise, among others
MDVIP $=$ MD-Value in Prevention .

location), socioeconomics (eg, income), supply of health services (eg, number of acute care hospital beds, specialists, PCPs), and health status (eg, Charlson Comorbidity Index [CCI], Psychiatric Diagnostic Group [PDG] score, number of inpatient admissions) in the pre period. Insurance plan types included exclusive provider organization, health maintenance organization, indemnity, point of service, preferred provider organization, and others. Regions of the United States were based on zip codes and assigned as Northeast, Midwest, South, or West. Median household income ranges were reported as high $(\geq \$ 45,809)$, medium-high $(\geq \$ 36,250$ and $<\$ 45,809)$, medium $(\geq \$ 29,875$ and $<\$ 36,250)$, or low $(<\$ 29,875)$ based on whether the median income in the individual's zip code area was in the highest, second-highest, third-highest, or lowest quartile in 2010, according to US Census records. Location was defined as living in a metropolitan area (population $\geq 50,000$ ) or other. Supply of health care services was defined based on the number of PCPs and specialists (per 100,000) and hospital beds (per 1000) in the member/nonmember zip codes of residence.

Health status was determined from medical claims diagnoses and place of service utilization and included the CCI $(=0,1+),{ }^{33}$ PDG $(=0,1+),{ }^{34}$ and the annual number of inpatient admissions. The CCI is a measure of the risk of 1-year, all-cause mortality attributable to selected comorbidities. PDGs are validated psychiatric diagnostic groups analogous to major diagnostic groups in the diagnostic-related group system but provide better classification of individuals with substance abuse and/or mental health disorders. Variables denoting missing data were included in the analyses; however, for brevity, results associated with missing data are not shown in the tables included in this article but are available upon request.

\section{Modeling}

Three sets of analyses were conducted to: (1) describe the characteristics of the members, (2) propensity score match randomly selected nonmembers to member characteristics, and (3) utilize multivariate regression models to estimate health care utilization and expenditures trends associated with the MDVIP program over time.

Descriptive. The first set of analyses categorized members by demographics, socioeconomics, supply of services, and clinical characteristics, and compared members to randomly selected nonmembers using univariate techniques without adjusting for case mix differences. This was done to determine if case mix differences needed adjustment between the groups prior to comparing the outcome variables. Chi-square and Student $t$ tests were used in these analyses to test for differences in categorical and continuous variables, respectively. All analyses were performed using SAS software, version 9.2 (SAS Institute Inc., Cary, NC).

Propensity matching. Propensity score matching was used to minimize case mix differences between members and nonmembers. In this second set of analyses, a logistic model was used to estimate the likelihood of enrolling in the program. The variables used in the model were those previously described. The propensity score for each sample individual was defined as each member's predicted probability of being in the program. This probability was then used to match members to similar nonmembers. Propensity score matching is a convenient and acceptable way to remove case mix differences when evaluating health and wellness programs. ${ }^{35,36}$

Second-stage regressions are often warranted to remove any remaining case mix differences after matching and to adjust for skewed medical expenditure distributions that are often common in health care. In a final set of medical expenditure statistical analyses, Exponential Conditional Mean (ECM) regression models were used to estimate the impact of the program on medical expenditure trends compared to nonmembers. $^{37}$

\section{Health care utilization}

Utilization of medical services was examined to provide a mechanism that could potentially drive changes in health care expenditure trends. Utilization metrics included annual rates of urgent care visits, ER visits, inpatient admissions, and readmissions comparing members to matched nonmembers.

\section{Changes in health care expenditures pre enrollment to years 1, 2, and 3 post enrollment}

ECM regression-adjusted health care expenditures were focused on pre enrollment total health plan paid medical and 
pharmacy costs, and patient co-payments compared to year 1 , year 2 , or year 3 post enrollment cost trends for members compared to matched nonmembers (difference-in-difference [DID] design). Membership fees paid by the members were not included in this evaluation as they are not relevant to the savings realized by the health plan.

\section{Cost savings ranges (DID) years 1, 2, and 3 post enrollment}

In addition to calculating overall changes in health care expenditures pre enrollment to post enrollment by year, the research team considered cost savings for the following ranges of savings: $\leq-\$ 1000 ;-\$ 999$ to $-\$ 500 ;-\$ 499$ to $-\$ 300$; $-\$ 299$ to $-\$ 150 ;-\$ 149$ to $-\$ 100 ;-\$ 99$ to $-\$ 50 ;-\$ 49$ to $-\$ 0.1$; $\$ 0.1$ to $\$ 49 ; \$ 50$ to $\$ 99 ; \$ 100$ to $\$ 149 ; \$ 150$ to $\$ 299 ; \$ 300$ to $\$ 499 ; \$ 500$ to $\$ 999$; and $\geq \$ 1000$. The team then determined the percentage of members who achieved cost savings or losses in each of the determined ranges for years 1,2 , and 3 .

\section{Characteristics associated with achieving $\$ 150$ per member per month (PMPM) or more cost savings}

Membership fees for MDVIP programs average about $\$ 150$ per month and are paid by the patient. For the MDVIP program to break even in total, cost savings from health care expenditures would need to meet or exceed \$150 PMPM. With the understanding from employer health management programs that prevention programs need 2 to 3 years to achieve positive ROIs, logistic regression models were used to determine characteristics associated with achieving \$150 PMPM or greater savings for years 1,2 , and 3 . The covariates already described were tested as predictors of positive savings.

\section{Results}

The initial study populations included 13,200 MDVIP members and 94,599 nonmembers, resulting in 11,396 propensity-matched members and nonmembers. Outliers were excluded at the top $0.5^{\text {th }}$ percentile of annual health care expenditures, resulting in 992 cases being deleted from the member and nonmember subgroups. The final study population included 10,186 (1 year), 5908 ( 2 year), and 3915 ( 3 year) members and nonmembers who met the eligibility criteria. As shown in Table 2, members differed from nonmembers on most of the demographic, socioeconomic, supply of services, and health status variables, demonstrating the need for propensity score matching to adjust for these case mix differences. Most of the significant differences in characteristics between members and nonmembers were eliminated or minimized with the matching methodology.

Utilization trends for years 1,2 , and 3 , investigated to document the potential source of health care savings, indicated significantly lower rates for ER visits and urgent care facility use (Table 3). Readmission rates were significantly different in year 1 only; there were no significant differences in inpatient admission utilization over the 3 years, but the absolute numbers of these were small.

Average medical and pharmacy expenditure trends for years 1, 2, and 3 indicated that members' cost trends exceeded those of nonmembers (matched, regression-adjusted, and excluding outliers): members' expenditures increased by $\$ 85.63$ PMPM in year $1(P<0.001$; standard deviation
[SD]: $\$ 45.20)$, by $\$ 29.16$ PMPM in year $2(P=0.23$; SD: $\$ 15.37)$, and by $\$ 2.17$ in year $3(P=0.94$; SD: $\$ 1.15)$ from their relative baseline expenditures prior to enrollment. Thus, health care expenditure trends over the 3 years indicated that, although members incurred significantly higher costs in year 1 , the gap narrowed over time such that by year 3 , members' and nonmembers' expenditures were similar.

The overall MDVIP program indicated a trend toward breaking even over the 3-year time period. To demonstrate cost ramifications of better health management, the research team tracked the percentage of members who achieved at least \$150 PMPM in savings (based on the average membership fee of about \$150 PMPM). In year 1, 24\% of individuals met this success measure; in year 2, 26\%; and in year 3,63\% met this minimum savings amount with most members (about 30\%) saving between \$150-\$299 PMPM and an additional 16\% saving between \$300-\$499 PMPM. In contrast to average health care expenditures for a population, percentages of those who meet a defined success measure (eg, exceeding the membership fee costs) provide an additional indication of the successful penetration of program impact among member subgroups.

Characteristics associated with achieving \$150 PMPM or greater savings changed over time (Tables $4 \mathrm{a}, 4 \mathrm{~b}$, and $4 \mathrm{c}$ ). In year 1 , those more likely to achieve savings had more chronic conditions, took greater numbers of prescription drugs, and were older (ages 55-64 years). In year 2, those more likely to achieve savings still had more chronic conditions but were younger (ages 35-64) and took more prescription drugs. By year 3 , however, those members who were more likely to achieve savings had no distinguishing age or chronic condition characteristics, an indication that savings were generated from prevention rather than chronic condition management.

\section{Discussion}

MDVIP has implemented a personalized medicine program focused on promoting healthy lifestyle behaviors and identifying and preventing disease, all while addressing care coordination and delivery of preventive care to populations of employees and their spouses. The model leverages the physician, who provides an annual 60- to 90-minute wellness visit that includes health screenings, diagnostics, and personalized coaching for nutrition and exercise. Smaller practices with fewer patients per physician allow for personalized attention and greater access to physicians 24 hours a day by phone, e-mail, or text, as well as availability for same-day appointments. Members experienced reduced utilization of ER and urgent care services and increased health care expenditure savings over time compared to nonmembers.

Extending the time of wellness visit lengths to 60-90 minutes removes one of the major barriers cited by physicians as hampering their ability to counsel on lifestyle modification. This is in contrast to the median visit length of 15.7 minutes in a typical PCP office covering a median of 6 topics. ${ }^{38}$ MDVIP recruits physicians who have an interest in wellness and prevention coaching in addition to their medical credentials. Ongoing physician education, accessible tools, and national conferences augment those skills. These opportunities address a second commonly acknowledged barrier of lack of self-efficacy in motivating patients to change lifestyle behaviors (especially for weight management). ${ }^{21}$ Evidence of 
Table 2. Demographics* For MDVIP Members and Random Controls: Prior to And After Propensity Score Matching

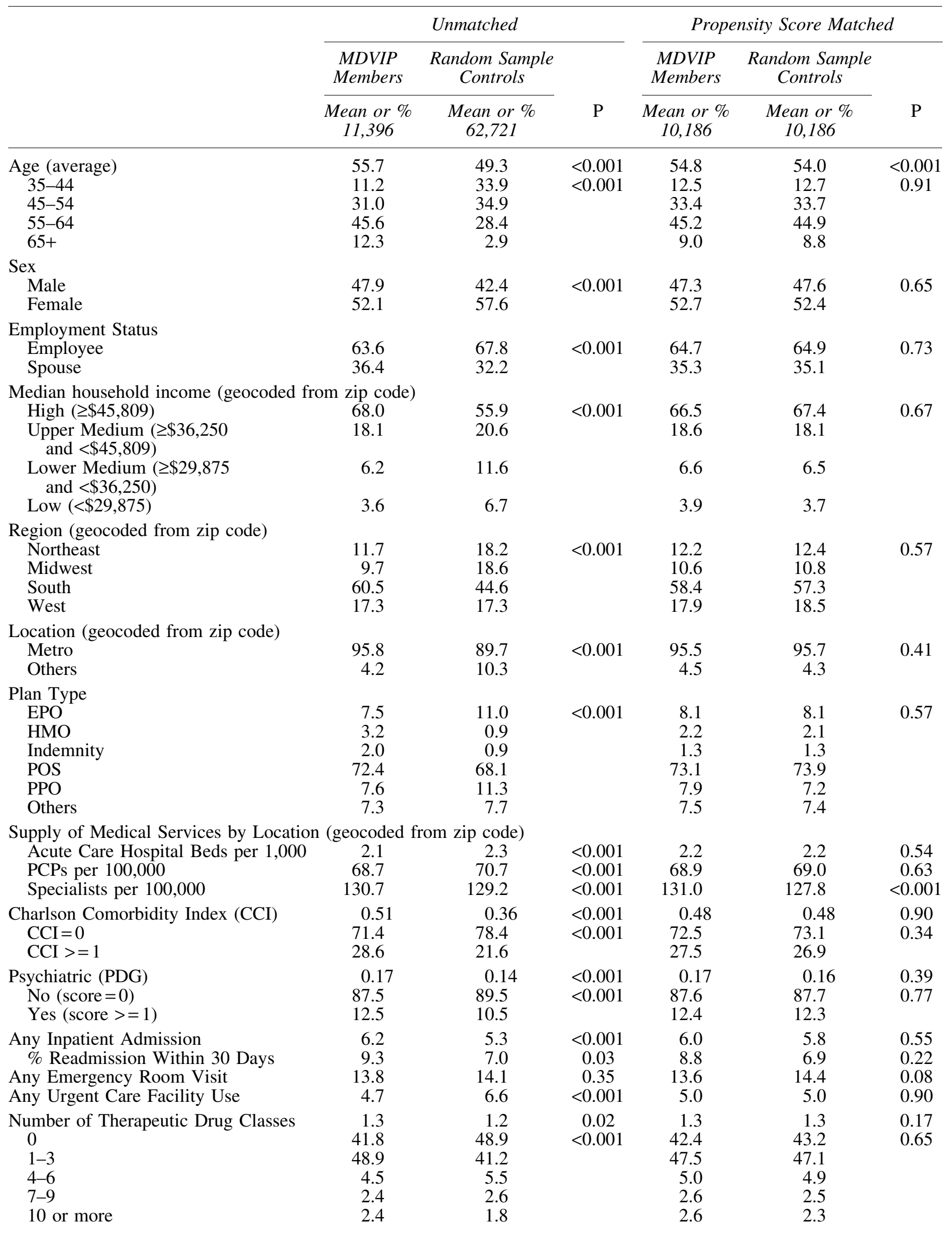

*Excluding outliers and zeros.

$\mathrm{EPO}=$ exclusive provider organization; $\mathrm{HMO}=$ health maintenance organization; $\mathrm{MDVIP}=\mathrm{MD}-\mathrm{Value}$ in Prevention; $\mathrm{PCP}=$ primary care physician; $\mathrm{PDG}=$ Psychiatric Diagnostic Group; POS = point of service organization; $\mathrm{PPO}=$ preferred provider organization . 
Table 3. Regression-Adjusted Health Care Utilization Years 1, 2, and 3 for Members AND MATCHED NONMEMBERS

\begin{tabular}{lccc}
\hline & $\begin{array}{c}\text { Members } \\
\%\end{array}$ & $\begin{array}{c}\text { Nonmembers } \\
\%\end{array}$ & $\mathrm{P}$ \\
\hline Year 1 & & & \\
$\quad$ Any IP Admission & 5.9 & 5.8 & 0.74 \\
$\quad$ Readmission Within 30 Days & 10.9 & 12.5 & $<0.001$ \\
Any ER Visit & 10.8 & 10.2 & 0.72 \\
Any Urgent Care Facility Use & 2.7 & 5.5 & $<0.001$ \\
Year 2 & & & 0.65 \\
Any IP Admission & 5.5 & 5.3 & 0.35 \\
Readmission Within 30 Days & 9.0 & 11.2 & $<0.001$ \\
Any ER Visit & 10.0 & 6.7 & \\
Any Urgent Care Facility Use & 3.2 & & 0.46 \\
Year 3 & & 7.6 & 0.63 \\
Any IP Admission & 7.1 & 10.1 & 0.001 \\
Readmission Within 30 Days & 9.0 & 17.3 & $<0.001$ \\
Any ER Visit & 14.6 & 10.1 & \\
Any Urgent Care Facility Use & 4.5 & & \\
\hline
\end{tabular}

Notes: 1 year $-\mathrm{N}=10,186 ; 2$ years $-\mathrm{N}=5908 ; 3$ years $-\mathrm{N}=3915$.

$\mathrm{ER}=$ emergency room; $\mathrm{IP}=$ inpatient.

the success of the MDVIP wellness visit model is documented in that most members take advantage of this membership benefit and schedule their annual wellness reviews. (Telephone communication; Dr. A. Klemes; October 2015.)

Spending more time with patients and physician counseling on behaviors have been associated with higher trust among patients. ${ }^{39}$ In turn, trust in one's physician has been linked to improvements in many factors, including patientphysician communications, satisfaction with health care, compliance with medical protocols, and continuity of care. Strengthening patient-physician relationships may be an important strategy to enhance patient engagement and mo-

Table 4A. Year 1 Characteristics Associated With ACHIEVIng \$150 Per Member Per Month (PMPM) In SAVIngs

\begin{tabular}{lcc}
\hline Characteristic & $\begin{array}{c}\text { Odds } \\
\text { Ratio }\end{array}$ & $\mathrm{P}$ \\
\hline Pre CCI $\geq 2$ & 2.87 & $<.0001$ \\
Pre PDG $\geq 1$ (Mental health) & 2.16 & $<.0001$ \\
Pre CCI 1 & 1.84 & $<.0001$ \\
Age 55-64 years & 1.27 & 0.01 \\
$\begin{array}{l}\text { Pre Number of Therapeutic } \\
\quad \text { Drug Classes 4+ }\end{array}$ & 1.27 & 0.005 \\
$\begin{array}{l}\text { Northeast } \\
\text { Female }\end{array}$ & 1.22 & 0.01 \\
$\begin{array}{l}\text { Pre Number of Therapeutic } \\
\quad \text { Drug Classes 1-3 }\end{array}$ & 1.17 & 0.002 \\
$\begin{array}{l}\text { Months of Follow-up } \\
\text { in Pre Period }\end{array}$ & 1.13 & 0.02 \\
HMO & 1.07 & $<.0001$ \\
$\quad$ & 0.41 & $<.0001$ \\
\hline
\end{tabular}

Notes: $\mathrm{N}=10,186$.

Break-even was considered \$150 PMPM, matching average member enrollment fees.

$\mathrm{CCI}=$ Charlson Comorbidity Index; $\mathrm{HMO}=$ health maintenance organization; $\mathrm{PDG}=$ Psychiatric Diagnosis Group. tivation to adopt healthy lifestyle behaviors. ${ }^{39}$ Managing lifestyle health risks remains especially important to patients in midlife and as they age to delay the onset of disease and disability and to facilitate the management of existing chronic conditions. ${ }^{23,24,40}$

Medical services utilization patterns indicated a significantly reduced use of the ER in years 2 and 3 and urgent care facilities in all 3 years. This is consistent with greater access to the patient's PCP, thus reducing the need to seek care in outside facilities. Neither inpatient admission rates nor readmission utilization were impacted by membership. It is noteworthy, however, that inpatient admissions and subsequent readmissions were relatively low given that this is an employee/spouse population with an average age of 55 years.

\section{Table 4B. Year 2 Characteristics Associated With Achieving \$150 Per Member Per Month (PMPM) In SAVINGs}

\begin{tabular}{lcc}
\hline Characteristic & Odds Ratio & $\mathrm{P}$ \\
\hline Pre CCI $\geq 2$ & 3.18 & $<.0001$ \\
Pre CCI $=1$ & 2.28 & $<.0001$ \\
Pre PDG $\geq 1$ (Mental health) & 2.16 & $<.0001$ \\
Age 35-44 years & 1.63 & 0.002 \\
Age 55-64 years & 1.58 & 0.001 \\
Age 45-54 years & 1.55 & 0.002 \\
PPO & 1.40 & 0.002 \\
Pre Number of Therapeutic & 1.15 & 0.03 \\
$\quad$ Drug Classes 1-3 & & \\
Employee & 0.80 & 0.001 \\
HMO & 0.49 & 0.005
\end{tabular}

Notes: $\mathrm{N}=5908$.

Break-even was considered \$150 PMPM, matching average member enrollment fees.

$\mathrm{CCI}=$ Charlson Comorbidity Index; $\mathrm{HMO}=$ health maintenance organization; $\mathrm{PDG}=$ Psychiatric Diagnosis Group; $\mathrm{PPO}=$ preferred provider organization. 
Table 4C. Year 3 Characteristics Associated With Achieving \$150 Per Member Per Month (PMPM) IN SAVINGS

\begin{tabular}{lcl}
\hline Characteristic & Odds Ratio & $\mathrm{P}$ \\
\hline Low Income Zip Code Area & 1.59 & 0.03 \\
Northeast & 1.34 & 0.009 \\
West & 1.32 & 0.004 \\
EPO & 1.31 & 0.04 \\
Female & 1.16 & 0.044 \\
Pre Number of Therapeutic & 0.85 & 0.02 \\
$\quad$ Drug Classes 1-3 & 0.77 & 0.005 \\
Pre CCI = 1 & 0.28 & 0.001 \\
Pre Number of Therapeutic & & \\
$\quad$ Drug Classes 4+ & & \\
\hline
\end{tabular}

Notes: $\mathrm{N}=3915$.

Break-even was considered \$150 PMPM, matching average member enrollment fees.

$\mathrm{CCI}=$ Charlson Comorbidity Index; $\mathrm{EPO}=$ exclusive provider organization.

Health care expenditure trends indicated increased medical costs for members in year 1 (primarily associated with increased prescription drug use - consistent with better management of chronic conditions). Ongoing health management and care coordination over years 2 and 3 minimized the differences between members and nonmembers such that by year 3 , the expenditures were similar. Although expenditure levels were nearly identical for members and nonmembers by the third year, one might suggest that consistent health management within the context of the MDVIP program would result in higher quality care for dollars spent.

These results are consistent with previously published MDVIP studies that demonstrated improved quality of care, increased compliance with recommended preventive services compared with traditional practices, ${ }^{31}$ and reduced hospital utilizations consistently over a 5-year time period among members versus nonmembers. ${ }^{30}$ The member/nonmember cost difference pattern over the 3 years is similar to the cost-saving trends experienced in employer-based health management programs' economic evaluations (ie, ROIs). Most welldesigned employer wellness/prevention programs require 2 to 3 years after program initiation to realize cost savings that exceed the investment of these programs. ${ }^{11-16}$ These health care cost trends also were similar to a previous study focused on Medicare Advantage beneficiaries enrolled in the MDVIP program. ${ }^{32}$ Members experienced significantly reduced utilization of ER services, inpatient admissions, and reduced health care expenditures through the first 2 years of the program.

It was of interest to characterize those members who achieved some level of cost savings over the years. The research team used the average membership fee of $\$ 150$ per month as the "cost of the program" and subsequently identified characteristics associated with those who exceeded this level in health care cost savings. In the first year, those with more chronic conditions, who used more prescription drugs, and who were older were more likely to achieve cost savings exceeding \$150 PMPM. Interestingly, however, by year 3 after enrollment in MDVIP, cost savings were generated primarily by younger members with fewer/ no chronic conditions and lower levels of prescription drug use, therefore likely associated with lifestyle behavior modification. Although the research team could not document changes in health risks, savings in employer-based programs for similar populations of employees/spouses are driven by improvements in health management, including risk reduction and helping individuals stay healthier over time. ${ }^{10,17}$ Increases in either health risks or disease prevalence for these younger members should have been reflected in increased health care expenditures rather than the observed decreases compared to nonmembers over time. ${ }^{3-7}$

Additional evidence for the moderating cost trends experienced by members compared to nonmembers is demonstrated in the proportion of members who achieved savings of \$150 PMPM or more across the years. In years 1 and 2,24\% to $26 \%$ achieved savings at this level. By year 3, $63 \%$ (most between $\$ 150$ and $\$ 299$ per month savings) had achieved positive savings at or above their monthly membership fees, marking a shift over time to increased proportions of the population achieving savings.

Limitations include a study population enrolled in health plans provided by a single insurer, which may not be generalizable to all employer health plans. The control population was randomly selected from UnitedHealthcare employer health plan databases and propensity matched to the MDVIP member populations. Although these statistical approaches are sophisticated and rigorous, unknown differences between the populations (eg, motivation regarding health attitudes) may not have been addressed. Strengths of the study include the large study populations and the longitudinal tracking over 3 years, along with the use of advanced statistical approaches.

These results demonstrate that a model of personalized preventive care focused on wellness and prevention and augmenting the physician-patient relationship can improve health management and reduce health care utilization and expenditures within populations of employees and their spouses. Health status at midlife is especially critical to maintaining health while aging, delaying disease and disability onset, managing existing chronic conditions, and enhancing quality of life and well-being during a lifetime. Personalized preventive care programs, such as that offered by MDVIP, provide an alternative primary care model that can help individuals achieve these health goals.

\section{Author Disclosure Statement}

Drs. Musich, Wang, Hawkins, and Klemes declared that, aside from their employment, they have no conflicts of interest with respect to the research, authorship, and/or publication of this article.

This study was sponsored by MDVIP.

\section{References}

1. ADP Research Institute. Why you should care about wellness programs. http://www.adp.com/tools-and-resources/ adp-research-institute/research-and-trends/ /media/RI/ whitepapers/Why-You-Should-Care-About-Wellness-Programs .ashx. Accessed February 5, 2014.

2. The Kaiser Family Foundation and Health Research \& Educational Trust. 2013 Employer Health Benefits Survey. http://kff.org/report-section/ehbs-2013-section-1/. Accessed February 5, 2014. 
3. Goetzel RZ, Anderson DR, Whitmer RW, et al. The relationship between modifiable health risks and health care expenditures. An analysis of the multi-employer HERO health risk and cost database. J Occup Environ Med. 1998;40:843854.

4. Kowlesar, NM, Goetzel RZ, Carls GS, Tabrizi MJ, Guindon A. The relationship between 11 health risks and medical and productivity costs for a large employer. J Occup Environ Med. 2011;53:468-477.

5. Yen L, Schultz A, Schnueringer E, Edington D. Financial costs due to excess health risks among active employees of a utility company. J Occup Environ Med. 2006;48:896905.

6. Goetzel RZ, Pei X, Tabrizi MJ, et al. Ten modifiable health risk factors are linked to more than one-fifth of employeremployee health care spending. Health Aff. 2012;31:24722484.

7. White J, Hartley SK, Musich S, Hawkins K, Ozminkowski RJ. A more generalizable method to evaluate the association between commonly reported health risks and healthcare expenditures among employers of all sizes. J Occup Environ Med. 2013;55:1179-1185.

8. Edington DW, Yen LT, Witting P. The financial impact of changes in person health practices. J Occup Environ Med. 1997;39:1037-1046.

9. Nyce S, Grossmeier J, Anderson DR, Terry PE, Kelley B. Association between changes in health risk status and changes in future health care costs. J Occup Environ Med. 2012;54:1364-1373.

10. Musich S, White J, Hartley SK, Bhattarai GK, Hawkins K, Ozminkowski RJ. A more generalizable method to evaluate changes in healthcare costs with changes in health risks among employers of all sizes. Popul Health Manag. 2014; 17:297-305.

11. Naydeck BL, Person JA, Ozminkowski RJ, Day BT, Goetzel RZ. The impact of the Highmark employee wellness programs on 4-year health care costs. J Occup Environ Med. 2008;50:146-156.

12. Grossmeier, J, Seaverson ELD, Mangen DJ, et al. Impact of a comprehensive population health management program on health care costs. J Occup Environ Med. 2013;55: 634-643.

13. Musich S, McCalister T, Wang S, Hawkins K. An evaluation of the well at Dell health management program: health risk change and financial return on investment. Am J Health Promot. 2015;29:147-157.

14. Henke RM, Goetzel RZ, McHugh J, Isaac F. Recent experience in health promotion at Johnson \& Johnson: lower health spending, strong return on investment. Health Aff (Millwood). 2011;30:490-499.

15. Baicker K, Cutler D, Song Z. Workplace wellness programs can generate savings. Health Aff (Millwood). 2010;29:304 311.

16. Lerner D, Rodday AM, Cohen JT, Rogers WH. A systematic review of the evidence concerning the economic impact of employee-focused health promotion and wellness programs. J Occup Environ Med. 2013;55:209-222.

17. Loeppke R, Edington DW, Beg S. Impact of the prevention plan on employee health risk reduction. Popul Health Manag. 2010;13:275-284.

18. Viera AJ, Kshirsagar AV, Hinderliter AL. Lifestyle modifications to lower or control high blood pressure: is advice associated with action? The Behavioral Risk Factor Sur- veillance Survey. J Clin Hypertens (Greenwich). 2008;10: 105-111.

19. Mellen PB, Palla SL, Goff DC, Bonds DE. Prevalence of nutrition and exercise counseling for patients with hypertension. J Gen Intern Med. 2004;19:917-924.

20. Hung OY, Keenan NL, Fang J. Physician's health habits are associated with lifestyle counseling for hypertensive patients. Am J Hypertens. 2013;26:201-208.

21. Visser F, Hiddink G, Koelen M, van Binsbergen J, Tobi H, van Woerkum C. Longitudinal changes in GPs' task perceptions, self-efficacy, barriers and practices of nutrition education and treatment of overweight. Fam Pract. 2008; 25:i105-i111.

22. Ruelaz AR, Diefenbach P, Simon B, Lanto A, Arterburn D, Shekelle PG. Perceived barriers to weight management in primary care-perspectives of patients and providers. J Gen Intern Med. 2007;22:518-522.

23. Fries JF. Aging, natural death, and the compression of morbidity. New Engl J Med. 1980;303:245-250.

24. Rula EY, Pope JE, Hoffman JC. Potential Medicare savings through prevention and risk reduction. Popul Health Manag. 2011;14:S35-S44.

25. Terry DF, Pencina MJ, Vasan RS, et al. Cardiovascular risk factors predictive of survival and morbidity-free survival in the oldest-old Framingham Heart study participants. J Am Geriatr Soc. 2005;53:1944-1950.

26. Wilcox BJ, He Q, Chen R, et al. Midlife risk factors and health survival in men. JAMA. 2006;296:2343-2350.

27. Chatterjee A, Kubendran S, King J, DeVol R. Checkup Time. Chronic disease and wellness in America. 2014. http:// assets 1b.milkeninstitute.org/assets/Publication/Research Report/PDF/Checkup-Time-Chronic-Disease-and-Wellnessin-America.pdf. Accessed October 5, 2014.

28. Pilkerton CS, Singh SS, Bias TK, Frisbee SJ. Changes in cardiovascular health in the United States, 2003-2011. J Am Heart Assoc. 2015;4:e001650.

29. Office of Disease Prevention and Health Promotion. Healthy People 2020. Older Adults. http://www.healthypeople.gov/ 2020/topics-objectives/topic/older-adults. Accessed October 7, 2015.

30. Klemes A, Seligmann RE, Allen L, Kubica MA, Warth K, Kaminetsky B. Personalized preventive care leads to significant reductions in hospital utilization. Am J Manag Care. 2012;18:e453-e460.

31. Seligmann RE, Gassner LP, Stolzberg ND, Samarasekera NK, Warth K, Klemes A. A personalized preventive care model versus a traditional practice: comparison of HEDIS measures. Int J Pers Cent Med. 2012;2:775-779.

32. Musich S, Klemes A, Kubica MA, Wang S, Hawkins K. Personalized preventive care reduces healthcare expenditures among Medicare Advantage beneficiaries. Am J Manag Care. 2014;20:613-620.

33. Charlson ME, Pompei P, Ales KL, MacKenzie CR. A new method of classifying prognostic comorbidity in longitudinal studies: development and validation. J Chronic Dis. 1987;40:373-383.

34. Ashcraft ML, Fries BE, Nerenz DR, et al. A psychiatric patient classification system. An alternaitve to diagnosisrelated groups. Med Care. 1989;27:543-557.

35. Fairies DE, Leon AC, Haro, JM, Obenchain RL. Analysis of Observational Healthcare Data Using SAS. Cary, NC: SAS Institute, Inc.; 2010. 
36. Seeger JD, Williams PL, Walker AM. An application of propensity score matching using claims data. Pharmacoepidemiol Drug Saf. 2005;14:465-476.

37. Diehr P, Yanez D, Ash A, Hornbrook M, Lin DY. Methods for analyzing health care utilization and costs. Annu Rev Public Health. 1999;20:125-144.

38. Tai-Seale M, McGuire TG, Zhang W. Time allocation in primary care office visits. Health Serv Research. 2007;42: 1871-1894.

39. Jones DE, Carson KA, Bleich SN, Cooper LA. Patient trust in physicians and adoption of lifestyle behaviors to control high blood pressure. Patient Educ Cons. 2012;89:57-62.
40. Musich S, McDonald T, Hirschland D, Edington D. Excess healthcare costs associated with excess health risks in diseased and non-diseased health risk appraisal participants. Dis Manage Health Outcomes. 2002;10:251-258.

Address correspondence to: Andrea Klemes, DO, FACE MDVIP

1875 NW Corporate Blvd, Suite 300 Boca Raton, FL, 33431

E-mail: aklemes@mdvip.com 